\title{
MODEL PENDUGA VOLUME POHON KAYU BAWANG (Disoxylum molliscimum Burm F.) DI PROVINSI BENGKULU
}

\author{
Tree Volume Estimation Model of Kayu Bawang \\ (Disoxylum molliscimum Burm F.) in Bengkulu Province \\ Agus Sumadi dan Hengki Siahaan \\ Balai Penelitian Kehutanan Palembang \\ Jl. Kol. H. Burlian KM. 6,5 Kotak Pos 179, Puntikayu, Palembang \\ Telp./Fax. (0711) 414864
}

Naskah masuk : 19 Desember 2009; Naskah diterima : 4 November 2010

\begin{abstract}
A tree volume estimation model of kayu bawang (Disoxylum molliscimum) in farm forestry was made in North Bengkulu based on data collected from 96 trees sample, 66 trees sample was used in model fitting and the remain 30 trees sample in model validation. The model construction was aimed for better estimation of forest plantation yield in order to perform effective forest management. The tree volume estimation model constructed in 5 form of regression formulas with diameter and height as independent variable. The best formula was selected by statistic test criteria of model construction and model validation i.e. coefficient of determination $\left(R^{2}\right)$, root mean square error (RMSE), average deviation (SR) and aggregate deviation (SA). Based on the criteria, the best formula of tree volume estimation model of kayu bawang is $V=0,0001027 D^{2,317} H^{0,239}$ with the value of $R^{2}=95,58 \%, R M S E=0,0386, S R=9,16 \%$ and $S A=0,09 \%$.
\end{abstract}

Keywords: Kayu bawang (Disoxylum molliscimum), volume estimation model, regression formula

\begin{abstract}
ABSTRAK
Model penduga volume pohon jenis kayu bawang (Disoxylum molliscimum) pada hutan rakyat di Bengkulu Utara disusun berdasarkan data dari 96 pohon sampel, 66 pohon sampel digunakan dalam penyusunan model dan 30 sampel pohon lainnya digunakan dalam validasi model. Penyusunan model bertujuan untuk pendugaan hasil hutan tanaman yang lebih baik dalam upaya mencapai pengelolaan hutan yang efektif. Model penduga volume disusun dalam 5 bentuk persamaan regresi dengan diameter dan tinggi pohon sebagai peubah bebas. Model terbaik diperoleh berdasarkan kriteria uji statistik dalam penyusunan dan validasi model, yaitu koefisien determinasi $\left(\mathrm{R}^{2}\right)$, akar rata-rata kuadrat simpangan (RMSE), simpangan rata-rata (SR), dan simpangan agregat (SA). Berdasarkan criteria tersebut, model penduga volume kayu bawang terbaik adalah $V=0,0001027 \mathrm{D}^{2,317} \mathrm{H}^{0,239}$ dengan nilai $\mathrm{R}^{2}=95,58 \%$, RMSE $=0,0386, \mathrm{SR}=9,16 \%$ dan $\mathrm{SA}=0.09 \%$.
\end{abstract}

Kata kunci : Kayu bawang (Disoxylum molliscimum), model penduga volume, persamaan regresi

\section{PENDAHULUAN}

Hutan di Indonesia setiap tahun mengalami penurunan potensi dan degradasi sehingga menyebabkan terjadinya penurunan pasokan kayu secara drastis. Kondisi kerusakan hutan telah menyebabkan terjadinya ketimpangan antara kebutuhan dan pasokan kayu. Kondisi tersebut mengakibatkan keberadaan hutan rakyat menjadi sangat penting sebagai salah satu pemasok atau penghasil kayu. Kayu bawang merupakan jenis kayu pertukangan yang banyak dikembangkan oleh masyarakat dalam bentuk hutan rakyat terutama di Bengkulu Utara.

Manajemen pengelolaan hutan rakyat jenis kayu bawang di Bengkulu Utara yang masih sederhana dan belum tersedianya perangkat yang dapat memudahkan dalam penghitungan potensi kayu yang dimiliki oleh masyarakat. Hal ini 
mengakibatkan perhitungan potensi kayu yang dihasilkan menjadi tidak akurat. Salah satu perangkat penting dalam penghitungan potensi kayu adalah model penduga volume.

Menurut Bambang dan Wahyono (1996), penaksiran dengan cara menggunakan angka bentuk batang yang umum digunakan sebesar 0,7 diduga merupakan salah satu sumber kesalahan dalam penaksiran, sehingga dapat mengakibatkan perbedaan yang cukup besar antara angka taksiran dengan angka sebenarnya. Dengan kondisi ini perlu dilakukan penelitian dengan tujuan mendapatkan model penduga volume pohon jenis kayu bawang yang memiliki ketelitian tinggi.

\section{BAHAN DAN METODE}

\section{A. Pelaksanaan Penelitian}

Penelitian dilaksanakan di hutan rakyat Bengkulu Utara pada bulan Agustus 2005. Data yang diperoleh dari 96 pohon model yang dibagi dalam dua kelompok, yaitu 66 data digunakan untuk penyusunan model dan sisanya 30 data digunakan untuk validasi model. Pohon model dipilih secara purposive sampling sehingga dapat mewakili sebaran kelas diameter dari diameter terkecil sampai dengan diameter terbesar. Pohon yang dipilih sebagai pohon model adalah pohon yang memiliki pertumbuhan normal, tidak terserang hama penyakit, serta memiliki tajuk dan batang normal. Pada pohon model dilakukan pengukuran diameternya setinggi dada (diameter at breast height $=d b h$ ), tinggi total, diameter pangkal dan ujung tiap seksi batang dan cabang dengan panjang seksi $1 \mathrm{~m}$ sampai diameter $7 \mathrm{~cm}$.

\section{B. Pengolahan Data dan Penyusunan Model}

Perhitungan volume pohon dilakukan dengan menjumlahkan volume seksi-seksi batang dan cabang pohon. Perhitungan volume seksi batang pohon dan cabang dengan menggunakan persamaan Smalian (Chapman dan Meyer, 1949) berikut:

$$
\text { Vs } \frac{\mathrm{Bp} B \mathrm{Bu}}{2} \times \mathrm{L} \quad \mathrm{Vp} \quad{ }_{\mathrm{i} 1}^{\mathrm{n}} \mathrm{Vs}
$$

$$
\text { Keterangan } \quad \begin{aligned}
\mathrm{Vs} & =\text { volume seksi batang }(\mathrm{m} 3) \\
\mathrm{Vp} & =\text { volume pohon }(\mathrm{m} 3) \\
\mathrm{Bp} & =\text { luas bidang dasar pangkal seksi }(\mathrm{m} 2) \\
\mathrm{Bu} & =\text { luas bidang dasar ujung seksi }(\mathrm{m} 2) \\
\mathrm{L} & =\text { panjang seksi }(\mathrm{m})
\end{aligned}
$$

Penyusunan model volume menggunakan analisis regresi dengan dua peubah bebas, yaitu diamater setinggi dada (dbh) dan tinggi pohon (Husch et al. 1972). Model yang diuji adalah model yang diajukan oleh Spurr, 1952; Burkhart, 1977; Romancier,1961; dan Schumacher \& Hall, 1933 dalam Krisnawati, 2007) (Tabel 1).

Tabel(Table) 1. Model yang diuji dalam pendugaan volume pohon kayu bawang (Model tested for kayu bawang tree volume estimation)

\begin{tabular}{|c|l|l|l|}
\hline No. & \multicolumn{1}{|c|}{ Nama model/Model } & \multicolumn{1}{|c|}{ Ekspresi/Expression } & \multicolumn{1}{|c|}{ Referensi/Reference } \\
\hline 1. & Constant form factor & $\mathrm{V}=\mathrm{b}_{0} \mathrm{D}^{2} \mathrm{H}$ & Spurr, 1952 \\
\hline 2. & Combined variable & $\mathrm{V}=\mathrm{b}_{0}+\mathrm{b}_{1} \mathrm{D}^{2} \mathrm{H}$ & Burkhart, 1977 \\
\hline 3. & $\begin{array}{l}\text { Generalized combined } \\
\text { variable }\end{array}$ & $\mathrm{V}=\mathrm{b}_{0}+\mathrm{b}_{1} \mathrm{D}^{2}+\mathrm{b}_{2} \mathrm{D}^{2} \mathrm{H}+\mathrm{b}_{3} \mathrm{H}$ & Romancier, 1961 \\
\hline 4. & Logarithmic & $\mathrm{V}=\mathrm{b}_{1} \mathrm{D}^{\mathrm{b} 2} \mathrm{H}^{\mathrm{b} 3}$ & $\begin{array}{l}\text { Schumacher and Hall, } \\
1933\end{array}$ \\
\hline
\end{tabular}

Keterangan (Remark) $: \mathrm{V}=$ volume pohon (volume tree), $\mathrm{D}=$ diameter setinggi dada (diameter breast height), $\mathrm{H}=$ tinggi total, (total height), b0, b1, b2, b2= koefisien regresi (regression coefficient)

Pada Model 1 hingga model 3 regresi dilakukan secara langsung pada data asli, sedangkan pada model 4 regresi dilakukan dengan terlebih dulu melakukan transformasi logaritma. Tetapi dalam perhitungan nilai-nilai uji statistik $\mathrm{R}^{2}$, RMSE, SA, dan SR, data terlebih dulu dikembalikan pada bentuk asli.

\section{Pemilihan Model Terbaik}

Model terbaik dipilih berdasarkan kriteria uji statistik sebagai berikut:

1. Koefisien determinasi $\left(\mathrm{R}^{2}\right)$

Koefisien determinasi merupakan proporsi variasi total di sekitar nilai tengah y yang dapat dijelaskan oleh variasi regresi (Draper 
\& Smith 1992). Semakin tinggi nilai $\mathrm{R}^{2}$, maka semakin besar variasi yang dapat dijelaskan. $\mathrm{R}^{2}$ dihitung dengan rumus:

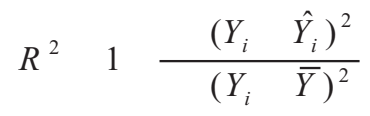

2. Akar rata-rata kuadrat simpangan (root mean squared error $=$ RMSE)

RMSE menyatakan akurasi dugaan (Huang et al. 2003) yang dinyatakan dengan rumus:

$$
R M S E \sqrt{\left.\frac{\left(Y_{i}\right.}{n} \hat{Y}_{i}\right)^{2}}
$$

\section{Validasi Model}

Simpangan rata-rata dan simpangan agregat digunakan untuk mengukur keakuratan suatu model yang besarnya ditentukan oleh selisih nilai hasil pendugaan dan hasil pengukuran. Semakin kecil nilai simpangan rata-rata dan simpangan agregat suatu model maka, keakuratan model tersebut semakin tinggi (Husch 1963). Nilai SR dan SA dihitung dengan rumus:

$$
\begin{aligned}
& S R \quad \frac{\frac{\mid Y_{i}}{Y_{i}} \mid}{Y_{i}} \times 100 \% \\
& S A \frac{\hat{Y}_{i} Y_{i}}{\hat{Y}_{i}} \times 100 \%
\end{aligned}
$$

Dengan: $\mathrm{n}=$ jumlah unit contoh, $\mathrm{p}=$ jumlah parameter, $\tilde{Y}=$ rata-rata nilai pengukuran, $Y_{i}=$ nilai pengukuran variabel ke-i, dan $\hat{Y}=$ nilai dugaan variabel ke-i

\section{HASIL DAN PEMBAHASAN}

\section{A. Sebaran Pohon Model}

Pohon model untuk penelitian ini dipilih secara purpossive sampling pada tegakan hutan rakyat yang tersebar di wilayah Bengkulu Utara. Pohon model untuk penyusunan model memiliki sebaran diameter antara 6.37 $34,33 \mathrm{~cm}$ dan tinggi total antara 7,3 - 23,7 m (Tabel 2). Sedangkan pohon model untuk validasi mempunyai sebaran diameter antara $6,37-33,12 \mathrm{~cm}$ dan tinggi antara 5,4 - 21,0 m (Tabel 3).

Tabel(Table)2. Sebaran diameter dan tinggi pohon penyusun model penduga volume kayu bawang (Diameter and height distribution of fitting tree model of kayu bawang)

\begin{tabular}{|c|c|c|c|c|c|}
\hline $\begin{array}{c}\text { Kelas diameter/ } \\
\text { Diameter class } \\
(\mathrm{cm})\end{array}$ & \multicolumn{4}{|c|}{ Tinggi pohon/Height $(\mathrm{m})$} & $\begin{array}{c}\text { Jumlah/ } \\
\text { Number of trees } \\
\text { (pohon) }\end{array}$ \\
\cline { 2 - 6 } & $5,0-9,9$ & $10,0-14,9$ & $15,0-19,9$ & $20,0-24,9$ & 3 \\
$5,0-9,9$ & 3 & & & & 7 \\
$10,0-14,9$ & 4 & 3 & & 2 & 15 \\
$15,0-19,9$ & & 10 & 3 & 4 & 19 \\
$20,0-24,9$ & & 5 & 10 & 2 & 16 \\
$25,0-29,9$ & & & 14 & 2 & 6 \\
$\geq 30,0$ & & 18 & 31 & 10 & 66 \\
\hline Jumlah/Sum & 7 & & & & \\
\hline
\end{tabular}

Tabel (Table) 3. Sebaran diameter dan tinggi pohon untuk validasi model penduga volume kayu bawang (Diametre and height distribution of validation tree model of kayu bawang)

\begin{tabular}{|c|c|c|c|c|c|}
\hline $\begin{array}{c}\text { Kelas diameter/ } \\
\text { Diameter class } \\
(\mathrm{cm})\end{array}$ & \multicolumn{4}{|c|}{ Tinggi pohon/Height $(\mathrm{m})$} & $\begin{array}{c}\text { Jumlah/ } \\
\text { Number of trees } \\
\text { (pohon) }\end{array}$ \\
\cline { 2 - 6 } & $5,0-9,9$ & $10,0-14,9$ & $15,0-19,9$ & $20,0-24,9$ & 2 \\
$5,0-9,9$ & 2 & & & & 4 \\
$10,0-14,9$ & 3 & 1 & 2 & & 7 \\
$15,0-19,9$ & 1 & 4 & 6 & 1 & 11 \\
$20,0-24,9$ & & 4 & 3 & 1 & 4 \\
$25,0-29,9$ & & & 2 & & 2 \\
$\geq 30,0$ & & 9 & 13 & 2 & 30 \\
\hline Jumlah/Sum & 6 & & & & \\
\hline
\end{tabular}




\section{B. Model Penduga Volume Pohon}

Model penduga volume pohon kayu bawang yang dikembangkan dalam pola hutan rakyat di Bengkulu Utara digunakan untuk menduga volume kayu yang dapat dimanfaatkan (merchantable volume). Model dibangun berdasarkan peubah bebas tinggi dan diameter pohon dengan empat persamaan regresi seperti tertera pada Tabel 4, masing-masing dengan nilai-nilai kriteria uji $\mathrm{R}^{2}$, RMSE, simpangan agregat (SA) dan simpangan rata-rata (SR).

Ketiga model pertama memiliki kesamaan bentuk, yaitu menggunakan variabel $\mathrm{D}^{2} \mathrm{H}$. Penambahan konstanta pada model pertama menjadi model 2 hanya meningkatkan nilai koefisien determinasi sebesar $1,11 \%$, artinya peningkatan keragaman yang diterangkan oleh model dengan penambahan konstanta tersebut tidak cukup berarti. Pada model 3, penambahan variabel $\mathrm{D}^{2}, \mathrm{D}^{2} \mathrm{H}$, dan $\mathrm{H}$ dapat meningkatkan koefisien determinasi hingga 4,58\%. Hasil uji signifikansi pada ketiga variabel tersebut variabel $\mathrm{D}^{2}$ mempunyai peran yang sangat nyata $(\alpha=0.000), \mathrm{D}^{2} \mathrm{H}$ berperan nyata $(\alpha=0,026)$, sedangkan $\mathrm{H}$ tidak berperan nyata $(\alpha=0,091)$.
Selain menggunakan kriteria uji $\mathrm{R}^{2}$ dan RMSE yang diperoleh dari data penyusun model, kriteria uji lain yang perlu diperhatikan dalam penyusunan model penduga volume pohon adalah simpangan rata-rata (SR) dan simpangan agregat (SA) yang merupakan kriteria uji yang diperoleh dari tahapan validasi model. Validasi model sangat penting dilakukan karena kualitas dari model fitting (berdasarkan data yang digunakan untuk menyusun model) belum tentu mencerminkan kualitas hasil prediksi model (berdasarkan independent data yang tidak digunakan untuk menyusun model)(Huang etal., 2003).

Berdasarkan nilai-nilai kriteria uji $\mathrm{R}^{2}$, RMSE, SR, dan SA, model penduga volume kayu bawang yang paling tepat adalah model 3 dan model 4. Nilai $\mathrm{R}^{2}$ dan RMSE kedua model hampir sama. Tetapi berdasarkan validasi model, nilai simpangan rata-rata (SR) dan simpangan agregat (SA) model ke-4 lebih kecil dibandingkan model 3. Nilai SA dan SR model 4 telah memenuhi kriteria sebagaimana disyaratkan oleh Chapman dan Meyer (1949) dan Husch (1963) yang menyatakan bahwa simpangan agregatif model penduga pohon sebaiknya tidak lebih dari $1 \%$ serta kriteria Spurr (1952) yang menyatakan bahwa simpangan rata-rata tidak lebih dari $10 \%$.

Tabel (Table) 4. Nilai $\mathrm{R}^{2}$, RMSE, SR dan SA model penduga volume pohon kayu bawang $\left(R^{2}, R M S E, S R\right.$ dan $S A$ value of kayu bawang tree model estimation)

\begin{tabular}{|c|l|c|c|c|c|}
\hline No. & \multicolumn{1}{|c|}{ Model } & $\begin{array}{c}\mathrm{R}^{2} \\
(\%)\end{array}$ & RMSE & $\begin{array}{c}\text { SR } \\
(\%)\end{array}$ & $\begin{array}{c}\text { SA } \\
(\%)\end{array}$ \\
\hline 1 & $\mathrm{~V}=0.0000351 \mathrm{D}^{2} \mathrm{H}$ & 89,78 & 0,0587 & 16,71 & 3,62 \\
\hline 2 & $\mathrm{~V}=0.0113+0.0000323 \mathrm{D}^{2} \mathrm{H}$ & 90,89 & 0,0554 & 16,09 & 0,22 \\
\hline 3 & $\begin{array}{l}\mathrm{V}=0.0187+0.000456 \mathrm{D}^{2}+0.000013 \mathrm{D}^{2} \mathrm{H}- \\
0.00494 \mathrm{H}\end{array}$ & 95,47 & 0,0391 & 10,65 & 1,36 \\
\hline 4 & $\mathrm{~V}=0,0001027 \mathrm{D}^{2,317} \mathrm{H}^{0,239}$ & 95,58 & 0,0386 & 9,16 & 0,09 \\
\hline
\end{tabular}

Tabel (Table) 5. Peringkat penilaian model penduga volume kayu pohon bawang (Tree volume estimation model rank of kayu bawang at Bengkulu)

\begin{tabular}{|c|c|c|c|c|c|c|c|}
\hline \multirow{2}{*}{ No. } & \multirow{2}{*}{ Persamaan/Equation } & \multicolumn{4}{|c|}{$\begin{array}{c}\text { Peringkat nilai persamaan/ } \\
\text { Rank of equation vallue }\end{array}$} & $\begin{array}{c}\text { Peringkat gabu- } \\
\text { ngan/Combination } \\
\text { of ranks }\end{array}$ \\
\cline { 3 - 6 } & $\mathrm{R}$ & 4 & 4 & 4 & 4 & 16 & 4 \\
\hline 2 & $\mathrm{~V}=0.0000351 \quad \mathrm{D}^{2} \mathrm{H}$ & 3 & 3 & 3 & 2 & 11 & 3 \\
\hline 3 & $\begin{array}{c}\mathrm{V}=0.0113+0.0000323 \mathrm{D}^{2} \mathrm{H} \\
0.0187+0.000456 \mathrm{D}^{2}+\end{array}$ & 2 & 2 & 2 & 3 & 9 & 2 \\
\hline 4 & $\mathrm{~V}=0,0001027 \mathrm{D}^{2,317} \mathrm{H}^{0,239}$ & 1 & 1 & 1 & 1 & 4 & 1 \\
\hline
\end{tabular}




\section{KESIMPULAN DAN SARAN}

\section{A. Kesimpulan}

Model penduga volume pohon kayu bawang dengan persamaan regresi sederhana dengan peubah bebas tinggi dan diameter pohon yang memiliki ketelitian tertinggi adalah $\mathrm{V}=$ $0,0001027 \mathrm{D}^{2,317} \mathrm{H}^{0,239}$ dengan nilai $\mathrm{R}^{2}=95,58 \%$, $\mathrm{RMSE}=0,0386, \mathrm{SR}=9,16 \%$ dan $\mathrm{SA}=0,09 \%$.

\section{B. Saran}

Model penduga volume pohon jenis kayu bawang bisa digunakan di lapangan untuk menduga volume pohon khususnya pada hutan rakyat di Bengkulu Utara atau kayu bawang di lokasi lain yang memiliki karakteristik pertumbuhan yang tidak terlalu berbeda. Penggunaan model penduga volume pohon untuk aplikasi di lapangan atau oleh masyarakat perlu dibuat tabel volume pohon kayu bawang berdasarkan persamaan model penduga volume pohon yang telah terbentuk.

\section{DAFTAR PUSTAKA}

Bambang E. D. dan D. Wahjono. 1996. Tabel Isi Pohon Jenis Rasamala (Altingia excelsa) di KPH Cianjur, Jawa Barat. Buletin Penelitian Huta. Bogor
Chapman, H.H. and W.H. Meyer. 1949. Forest Mensuration. McGraw-Hill Book Company, Inc, New York.

Draper N. Smith, H. 1992. Analisis Regresi Terapan. Bambang Sumantri, penerjemah. Jakarta: Gramedia Pustaka Utama. Terjemahan dari: Applied Regression Analysis.

Huang, Yang Y., Wang Y. 2003. A critical look at procedures for validating growth and yield models. Di dalam: Amaro A, Reed D, Soares P, editor. Modelling Forest Systems. London: CABI Publishing.

Husch, B., C. I. Miller dan T. W. Beer. 1972. Forest Mensuration. Second Edition. The Ronald Press Company. New York.

Husch, B. 1963. Forest Mensuration and Statistics. Ronald Press Company, New York.

Krisnawati, H. 2007. Modelling stand growth and yield for optimizing management of Acacia mangium Willd. plantation in Indonesia. Disertasi. University of Melbourne.

Spurr, S.H. 1951. Forest Inventory. The Roland Press Company. New York. 